\title{
Yield Management: A Tool for Capacity-Constrained Service Firms
}

\author{
SHERYL E. KIMES \\ CORNELL UNIVERSITY
}

\section{EXECUTIVE SUMMARY}

Airlines typically sell their seats for a variety of different fares. If customers make reservations early, low fares might be available, but if customers call at the last minute, they will probably have to pay the full fare. Since deregulation, nearly all airlines have been using a technique called yield management. Yield management allows the airlines to allocate their fixed capacity of seats in the most profitable manner possible. Since the airline's inventory of seats is perishable, the airlines must have a method of quickly and accurately allocating potential demand to capacity. The airline industry has been in the forefront of using yield management, but yield management has potential application to any firm constrained by capacity. Other services which have adopted yield management include the lodging, rental car, delivery service, rail and cruise line industries.

The objective of yield management is to maximize the revenue or yield of the firm. A good yield management system will help the firm decide how much of each type of inventory (whether it be seats on an airplane, rooms in a hotel, or cars in a rental car fleet) to allocate to different types of demand. This article attempts to structure the concept of yield management by reviewing current literature, classifying types of solution approaches, discussing the managerial implications of yield management and presenting a future research agenda. While corporate research on yield management has been performed, most firms are understandably reluctant to share the results of their research with others. Operations management researchers could assist small and medium sized capacity-constrained firms by developing simple and accurate yield management techniques. The intent of the paper is to focus attention on the yield management and stimulate practical and theoretical research in this area.

\section{INTRODUCTION}

Yield management, a method for managing capacity profitably, has recently gained widespread acceptance in the airline and hotel industries. Yield management is a method which can help a firm sell the right inventory unit to the right type of customer, at the right time, and for the right price. Yield management guides the decision of how to allocate undifferentiated units of capacity to available demand in such a way as to maximize profit or revenue. The problem then becomes one of determining how much to sell at what price and to which market segment.

The concepts behind yield management can easily be seen in the airline industry. Yield refers to either yield per available seat mile or yield per revenue passenger mile. Airlines typically offer several classes of service such as full-fare, maxisavers, and super-savers. The airlines would prefer filling their planes with full-fare customers, but since this rarely occurs, they try filling the plane by offering reduced fare incentives. A tradeoff develops between the desire for high capacity utilization (or load factor) and the desire for selling seats at the maximum price. Due to the perishable nature of an airline's inventory, an empty seat represents an opportunity cost. The airlines must decide how many discount fares to sell while at the same time making sure they have enough seats left to sell to later-booking full-fare passengers. 
Many airlines have solved this problem with yield management and use a combination of seat inventory management and pricing tools to achieve their goal of maximum revenue. Since more revenue can be obtained from a relatively fixed capacity, yield management becomes a very attractive option. The airline industry was the first to systematically address the capacity allocation problem with yield management and has achieved a great deal of success (Lloyd's (1985), Cross (1986), Belobaba (1987)). Many airlines report increases in revenue of 5 percent or more after starting a yield management program (Lloyd's (1985), Belobaba (1987)).

Other firms, most notably in service industries such as lodging, car rental and freight transport, have noticed the success of yield management in the airline industry and have tried adapting yield management concepts to their particular industries. Extending the airline definition of yield to other industries would result in yield per available inventory unit. For example, yield for a hotel would be measured as revenue per available room. While these other industries are certainly not identical, they do share one characteristic: fixed capacity. In addition, all have easily segmented markets and stochastic demand for each type of service.

When service firms are constrained by capacity (i.e., transportation, lodging, health care, entertainment, and food service), financial success is often a function of management's ability to use capacity efficiently. Yield management in capital-intensive service industries such as airlines is often equated with revenue (or yield) maximization because of the high fixed-cost nature of the industry. The marginal costs of selling another seat and transporting the passenger in it are so small compared to the marginal revenue as to render the marginal costs inconsequential.

Lovelock (1984) proposed a concept similar to yield management, by advocating capacity allocation to different market segments over time. He believed that, rather than measuring capacity utilization (whether load factor, occupancy, or another parameter), service firms should measure the Asset-Revenue Generating Efficiency (ARGE) of the firm. The ARGE, the product of capacity utilization and the unit price efficiency rate, provides a measure of both productive efficiency and pricing efficiency. This concept is very similar to yield management since both combine capacity utilization and pricing efficiency.

In this paper, I will address the characteristics of the yield management, identify basic solution techniques and associated problems, describe possible implementation concerns, and discuss possible directions for future research.

\section{APPROPRIATE SITUATIONS FOR EFFECTIVE YIELD MANAGEMENT APPLICATION}

Yield management techniques are appropriate (1) when a firm is operating with a relatively fixed capacity, (2) when demand can be segmented into clearly-identified partitions, (3) when inventory is perishable, (4) when the product is sold well in advance, (5) when demand fluctuates substantially, and (6) when marginal sales costs and production costs are low, but capacity change costs are high. Although these traits are characteristic of the firms in which yield management is used, they are also characteristic of firms which have a problem of allocating fixed capacity efficiently. These characteristics are necessary conditions for the proper adoption of yield management. Each characteristic will be further discussed below. 
(1) Relatively fixed capacity. Since the focus of yield management is efficient allocation of shared fixed capacity, it is only appropriate for firms which cannot quickly adapt available capacity to available demand. For example, if all rooms in a hotel are occupied, another room cannot easily be added, although the customer may be accommodated in a sister hotel in a different part of the city. For airlines, if all seats on a flight are occupied, the plane cannot be enlarged, but it may be possible to put the passenger on a later flight. Essentially, capacity is fixed, although there may be some limited flexibility.

(2) Ability to segment markets. In order for a yield management program to be effective, the firm must segment its market into different types of customers. For example, the airline industry distinguishes between time-sensitive and pricesensitive customers by requiring a Saturday night stay for most discounted fares. Basically, the business must know which customers are most likely to use variously-priced classes of service, and must develop different marketing strategies for each market segment.

(3) Perishable inventory. One of the key factors distinguishing service firms from manufacturing firms is that the inventory is perishable. In the case of capacity-constrained service firms, the problem is even more severe in that additional capacity cannot be obtained. Seats unsold on an airplane, rooms unsold in a hotel, or cars unrented at a rental car agency all represent spoiled or wasted inventory. If a firm can minimize its inventory spoilage, it will operate much more efficiently.

(4) Product sold in advance. One of the capacity management tools that service businesses use is a reservation system in which units of inventory are sold in advance of actual use. Reservations systems provide the firm with some measure of security, in that they know that their capacity will be used in the future, but when the product is sold in advance, the manager is also faced with uncertainty. The manager must decide whether to accept an early reservation of a customer who wants low price, or wait and see if higher paying customers will appear. With a good yield management system, this type of situation can be addressed.

(5) Fluctuating demand. Many service firms face highly erratic demand patterns, and managers must devise some method of dealing with this uncertainty. Yield management can be used to help temper some of the demand fluctuations by increasing utilization during slow demand times (by decreasing price), and by increasing revenue during times of high demand (by increasing price). If a manager knows when demand peaks and valleys will occur, he/she will be better able to plan for them.

(6) Low marginal sales costs/high marginal capacity change costs. For a yield management system to be effective, marginal sales costs, the cost of selling an additional unit of inventory, must be low, but marginal capacity change costs should be high. For capacity-constrained firms, providing additional capacity is a very expensive proposition, but selling another unit of available capacity is relatively inexpensive. 


\section{COMPONENTS OF THE PROBLEM}

Yield management must address a myriad of problems including:

(1) demand patterns for various rates/fares,

(2) overbooking policy,

(3) demand elasticities,

(4) information system.

Of these problem components, the existence of an accurate information system is most critical, because without it, none of the other information will be available for use.

(1) Demand patterns. Information on historical demand patterns for various rate classes must be available. Most yield management systems in commercial use are based strictly on historical demand patterns. Generally, in the airline industry, demand is assumed to follow a normal distribution (Belobaba (1987)). The probability distribution of demand in other industries has not yet been rigorously studied. In addition, information on the booking pattern for each rate class must be obtained in order to better understand the behavior of the different customers. Generally, bookings have been assumed to follow a random Poisson probability distribution (Beckman (1958), Thompson (1961), Taylor (1962)). Finally, the demands for different rate classes must be studied to determine the possibility of correlation among rate classes. By knowing the interaction between rate classes, a firm can better understand how many inventory units which could have been sold at a high price may be cannibalized by selling too many inventory units at a lower price.

Several other assumptions often made include the forgetfulness property which states that the probability of cancellation is not dependent upon when the reservation was made, and that customers will freely upgrade or downgrade their class of service (Thompson (1961)). The latter hypothesis may be based on unrealistic price elasticity assumptions which will lead to inaccurate model results.

(2) Overbooking policies. Overbooking policies must also be assessed and include information on historical no-show rates and current policies on overbooking. The overbooking problem has been studied rather extensively (Rothstein (1971), Rothstein (1974), Schlifer and Vardi (1975), Ladany (1976), Ladany (1977), Hersh and Ladany (1978), Rothstein (1985), Alstrup et al. (1986)). Generally, cancellations are assumed to follow a binomial distribution, although this assumption has not been rigorously tested in all industries. The overbooking policy must be integrated with the yield management program or sales will be limited to an arbitrarily low level.

(3) Demand elasticities. The effect of price changes on demand must also be assessed. As mentioned above, yield management consists of both pricing and inventory management components. Although pricing has a direct impact on revenues, most firms cannot change price without taking the reactions of competitors into account. To fully use the potential of a yield management system, management must know the elasticity of demand for various rate classes and be able to make corresponding changes. 
(4) Information system. The biggest problems facing a firm contemplating adoption of a yield management program are data availability and accuracy. A completely computerized management information system is not required; what matters is the type and accuracy of data collected. Without a good information system, the yield management system will be doomed to failure. For example, an airline which does not keep track of the number of discount seats sold for a particular flight can encounter a severe problem when all of the potential passengers arrive at the gate only to find an extremely-overbooked plane.

\section{SOLUTION TECHNIQUES}

Yield management solution techniques vary in sophistication, but generally fall into four different categories: (1) mathematical programming, (2) economics-based, (3) threshold curve, and (4) expert systems. One of the key characteristics of the yield management problem is that it must be solved repeatedly. Because of this, any solution method must be fast, fairly accurate and not too expensive. Optimality is desirable, but may not be as important as solving the problem quickly with a fair degree of accuracy. Due to computer limitations, marginal revenue models and threshold curve approaches seem to be the most popular methods. Mathematical programming and expert systems approaches may produce better results than the popular models currently in use, but the time and computer resources necessary to solve the problem on a frequent basis, have reduced their attractiveness to decision-makers. Still, if the computational problems can be overcome, these approaches offer viable alternatives.

Belobaba (1987) gives a comprehensive review of yield management research in the airline industry. His description and approach to the problem provide an excellent framework from which to address the issue of yield management. Most published research on yield management has occurred in the airline industry, and this will be the focus of the discussion on methodology. Although the research was developed for the airline industry, it is certainly applicable to yield management problems in other industries. Before describing each of the methods, terminology associated with yield management will first be defined, and the framework developed by Belobaba will be discussed.

\section{Terminology}

\section{Buckets of Inventory, Booking Limits and Booking Curves}

Different types of inventory (be they seats, rooms, or cars) are commonly referred to as buckets of inventory. Frequently, an inventory bucket will have a booking limit, which refers to the maximum number of inventory units of that bucket which can be sold. The booking curve refers to the way in which reservations for an inventory bucket are made over time.

\section{Types of Rate Classes}

Rate classes within the shared fixed capacity can be considered to be either distinct or nested (Belobaba (1987)). Shared fixed capacity might refer to the coach cabin of a plane (Belobaba (1989)), or all similar rooms within a hotel. Distinct rate classes provide separate inventories of capacity (or buckets) for each rate class. For example, an airline might decide to sell 20 full-fare coach seats, 20 super-saver seats, and 20 max-saver seats. The concept of distinct rate classes is related 
to the classic aircraft design problem of where to locate the partition between classes, although in the case of yield management, all capacity is shared. The booking limits for each capacity bucket must sum to the shared capacity, but if overbooking is allowed, should sum to the maximum number of reservations allowed for the shared capacity (Belobaba (1989)). This type of system sets aside a fixed amount of inventory for each rate class and does not allow for allocating unsold lower-price inventory to higher-paying customers.

With nested systems, a high-rate request will not be refused if inventory is available at lower rates. Booking limits are binding for lower rate classes, but do not exist (other than for service capacity) for the highest rate class. For example, consider the hypothetical case of a 100 room hotel with four rate classes (ranked from highest rate to lowest rate): transient, corporate, government and group (Figure 1). The maximum number of rooms which could ever be sold to the highest rate class (transient) is 100. This is referred to as the booking limit. After looking at relative price and demand, management might decide to protect-at least 20 rooms for this class of service. This is referred to as the nested protection level. Next, if management wanted to determine the booking limit for the corporate guests, the nested protection level of the transient guests would be subtracted from the booking limit for that class (100-20) and 80 rooms would be the maximum number of rooms which should ever be booked for the corporate class. This logic continues for all other rates of service.

FIGURE 1

NESTED RESERVATION SYSTEM

\begin{tabular}{|c|c|c|}
\hline Transient & \multicolumn{2}{|c|}{$\begin{array}{l}100 \text { Rooms for Transient, Corporate, } \\
\text { Government, and Group }\end{array}$} \\
\hline Corporate & $\begin{array}{l}80 \text { Rooms for } \\
\text { and Group }\end{array}$ & orate, Government \\
\hline Government & $\begin{array}{l}45 \text { for Transient } \\
\text { and Corporate }\end{array}$ & $\begin{array}{l}55 \text { for Government } \\
\text { and Group }\end{array}$ \\
\hline Group & $\begin{array}{l}50 \text { for Transient, Corporate } \\
\text { and Government }\end{array}$ & 40 for Group \\
\hline
\end{tabular}

Nested Protection

Booking Limit 
When static solution approaches are used, the problem is solved once and is not updated when additional information becomes available. Dynamic approaches allow booking limits to be revised as actual bookings are accepted. In reality, many dynamic approaches simply involve resolving the static problem when additional information becomes available. When addressing the dynamic problem, the value of accepting a current reservation relative to the decrease in expected total revenue from removing one item from the available inventory of the service can be assessed.

\section{Common Assumptions}

Demand is assumed to be either deterministic or probabilistic. Deterministic demand is easier to model, but probabilistic demand is more realistic. Research in airline seat allocation among distinct fare classes generally assumes that demand for each fare class is separate and non-correlated, that cancellations and no-shows do not exist, and that rejected revenues represent a loss of revenue (Belobaba (1987)).

Early research in the airline industry tended to overlook the relationship between overbooking and seat inventory control and made some assumptions which were not necessarily true. For example, refused requests do not necessarily represent lost revenue, since passengers may upgrade or switch to another flight on the same airline. In addition, the possibility of correlation of demand among fare classes exists, but this problem has not been systematically addressed.

The ideal method should be efficient, adaptable and match the solution with the practical constraints of the problem which mostly stem from data availability and computer capability. The method should also incorporate realistic demand assumptions and should use nested fare classes.

\section{Mathematical Programming Approaches}

A widely-used approach for solving the static problem is mathematical programming (Rothstein (1971), Hersh and Ladany (1978), Alstrup et al. (1986)). Mathematical programming works well with distinct rate classes, but will not necessarily give the true revenue-maximizing allotments for a nested reservations system. Mathematical programming and network approaches (Glover et al. (1982)) with multiple rate classes, flight legs and customer itineraries have been developed but suffer from problems in dealing with nested rate classes, using deterministic demand, and computational power required.

\section{Linear Programming}

The linear programming formulation of the yield management problem is fairly simple, with an objective of maximizing revenue subject to constraints on (1) the sum of the number of units of inventory allocated to each inventory bucket must be less than the capacity of the service, and (2) the number of units of inventory allocated to an inventory bucket must be Less than the expected demand for that inventory bucket. 
$\operatorname{MAX} \sum_{i=1}^{n} r_{i} x_{i}$

subject to:

$$
\begin{aligned}
& \sum_{i=1}^{n} x_{i} \leqslant C \\
& x_{i} \leqslant d_{i} \text { for all } i \\
& x_{i}, d_{i} \geqslant 0 \\
& i \quad=\text { Rate class. } \\
& x_{i}=\text { Number of items sold in rate class } i . \\
& d_{i}=\text { Demand for rate class } i . \\
& r_{i}=\text { Revenue from selling items at rate } i . \\
& C=\text { Capacity of service. }
\end{aligned}
$$

Although the linear programming solution can be found, the assumption of deterministic demand makes the solution to the problem unrealistic. In addition, most basic linear programming formulations of the problem assume distinct, rather than nested rate classes.

\section{Probabilistic Linear Programming}

An optimal solution can be found using probabilistic linear programming, but unfortunately, the computational intensity of such an approach may render it an impractical solution method. The basic linear programming formulation is modified to include the demand constraints in the objective function (although in a probabilistic form) with the objective of maximizing expected revenue. Capacity constraints and binary integer restrictions on all decision variables are the only constraints on the objective function.

$$
\operatorname{MAX} \sum_{j=1}^{m} \sum_{i=1}^{n} p_{i j} r_{i j} x_{i j}
$$

Subject to:

$$
\sum_{j-1}^{m} \sum_{i-1}^{n} x_{i j} \leqslant \sum_{j=1}^{m} C_{j}
$$

$\mathrm{i}=$ Rate class.

$\mathrm{j}=$ Inventory item.

$x_{i j}=0$ if item $\mathrm{j}$ not sold at rate $\mathrm{i}$,

$=1$ if item $\mathrm{j}$ sold at rate $\mathrm{i}$.

$\mathrm{p}_{\mathrm{i}]} \quad-$ Probability of selling item $\mathrm{j}$ at rate $\mathrm{i}$.

$\mathrm{r}_{\mathrm{ij}}=$ Revenue from selling item $\mathrm{j}$ at rate $\mathrm{i}$.

$\mathrm{C}_{\mathrm{j}}=$ Capacity of service.

Solution of this problem is very computationally intense, and solution of even a simple problem can lead to an enormous and unworkable number of decision variables (Williamson (1988)). The number of decision variables is equal to the number of inventory items multiplied by the number of rate classes. For example, a 100-seat plane with five rate 
classes would have 500 binary decision variables. Although the solution to the problem is optimal, it is not at present a practical technique for repetitive solution of the yield problem. As with simple linear programming, most probabilistic linear programming approaches are based on distinct rate classes.

\section{Dynamic Programming Approaches}

Because of the repetitive, sequential, and probabilistic nature of the yield management problem, many researchers have attempted to model the problem using stochastic dynamic programming (Rothstein (1971), Hersh and Ladany (1978), Alstrup et al. (1986)). Most early research applied this approach to the overbooking problem, although it could easily be extended to the yield management problem. Generally, the objective is to maximize expected revenue subject to operating constraints with states defined as the demand (or reservations) recorded at any given time prior to the service delivery. Stages are defined as time prior to service delivery. Transition probabilities are based on the probability distributions of demand for reservations, cancellations, and no-shows. The computational intensity of this approach leads to solution difficulties given current computing capabilities.

\section{Network Approaches}

Glover et al. (1982) modeled passenger itineraries for Frontier Airlines as a network flow problem. Given a daily forecast of the demand for passenger itineraries at the various fare classes, they sought to find the passenger itinerary and associated fare-class mix on each segment of each flight that would maximize revenue for that day.

The problem was modeled as a minimum cost (maximize profit) network flow diagram with side constraints. The forward arcs designated flight legs, and represented the number of passengers on a flight segment. The upper bound for each forward arc was limited by aircraft capacity. The backward arcs represented the passenger itineraries by fare class and were defined as the number of passengers on each passenger itinerary at each fare class. The flow on the backward arcs were limited by the demand for the passenger itinerary and fare class. Generally, the network formulation was found to be too loose, and the authors found that additional constraints were needed.

The model was tested for Frontier Airlines for 600 flights with 30,000 passenger itineraries. An additional 1800-2400 side constraints were also imposed. Computer solution was fast and was conducive to frequent, interactive runs. The linear programming formulation of the same problem would have required 200,000 variables with 3,000 constraints, and solution would be much too time-consuming for any practical implementation.

Wollmer (1989) extended the network approach of Glover et al. (1982) by including probabilistic demand and multiple flight legs. Wollmer (1989) first formulated a probabilistic linear programming model similar to the one given above, reformulated it to a network flow approach, and finally solved the problem as an acyclic network.

The beginnings and ends of flight legs were represented as nodes. Arcs corresponded to a seat $k$ being sold at fare $\mathrm{j}$. Maximum flow on an arc was set at 1 , while minimum flow was 0 . Arc lengths were equal to the expected marginal revenue from selling seat $\mathrm{k}$ at fare $\mathrm{j}$. Any probability distribution could be used with the model.

Wollmer (1989) showed that the expected revenue for an aircraft could be represented as a function of the number of 
empty seats on each leg. The acyclic network possessed a large number of arcs (number of seats times the number of fares), but only a few needed to be present during solution. The problem became one of solving a series of longest path problems in a relatively small network.

\section{Economics Approaches}

\section{Marginal Revenue Models}

Early research in the airline industry (Littlewood (1972)) showed that at any point in time, an airline should protect a certain number of seats for potential high fare demand, to the point at which the expected revenue from an additional protected high fare seat was equal to the actual fare level of the lower fare class. This indifference point determined the optimal number of seats to allocate. The optimal seat allocation occurs when the marginal revenue for the last seat sold in one fare class is the same as for another fare class. This point, lambda, is the Lagrange multiplier and represents the marginal revenue for the last seat allocated to each fare class (Belobaba (1987)).

Belobaba developed the expected marginal seat revenue (EMSR) model to address both the static and dynamic nested seat allocation problem. The objective of the model was to incorporate probabilistic demand into a seat inventory control method that could be applied to multiple fare classes on a single flight leg in a nested reservation system. He assumed normally distributed demand, that demand densities for different fare classes were not significantly correlated and that the number of requests received for various fare classes during different periods were not correlated.

With the nested problem the seat inventory problem is "to determine how many seats not to sell in the lowest fare classes and to retain for possible sales in higher fare classes closer to departure day" (Belobaba (1987), 120). The model is directed at finding protection levels for higher fare classes which can then be converted into booking limits for lower fare classes. The protection limits are the maximum number of seats that should be retained for a particular fare class (and available to all higher fare classes). Booking limits are the maximum number of seats that may be sold to a fare class, including all lower fare classes with smaller booking limits. The booking limits for the highest fare is equal to the capacity of the cabin. The protection level for a higher fare class is the difference between its booking limit and that of the next lower class. In the initial stages of this model, he assumed no vertical or horizontal choice shifts, and no cancellations or no-shows. Since he assumed a normal probability distribution, the probabilities are found by determining the z-score and the value corresponding to it. Obviously, any probability distribution could be used with this model.

In general, solution models that treat classes as distinct inventories (as in mathematical programming) can produce less than optimal results when applied to a nested fare structure. The logic of accepting all lower fare requests as long as the lower fare exceeds the expected marginal revenue of the higher marginal revenue fare class being displaced suggests that the EMSR will generate at least as much in total expected revenue as the stand-alone solution applied to nested fare classes for a range of demand and booking assumptions.

The static EMSR approach can be applied to the dynamic problem by updating information over time. Additional information on requests at a given time are required, and basically the static model is applied repetitively over time with 
the revised input data. Both the static and dynamic approaches can be modified to include cancellations, no-shows, overbooking and passenger choice shifts.

Another possible extension is to the virtual nesting problem. Most airlines operate on a hub and spoke system and are more concerned with origin-destination itineraries than with individual flight legs. These airlines maintain a primary inventory of 5-8 fare classes while establishing a relationship between a fare class and the itinerary combination and one of a much larger number of hidden inventory classes. The classes are internal to the reservation system. The objective is to maximize expected revenue over an airline's complete network of routes and flights and to give the airline greater control over seats made available to passengers that generate different revenue levels for the airline. Virtual inventory classes (VIC) are associated with each specific flight leg and itinerary. The EMSR can be applied to the VIC concept, by nesting the VICs hierarchically for each flight so that the top inventory class cannot be shut down without closing down all lower-ranked classes. EMSR can be used as long as the demand density for each inventory class can be determined. EMSR can then be used to determine the optimal protection levels and booking limits for each VIC and flight leg. Adding in overbooking and upgrades causes this to become a heuristic rather than optimizing approach.

Belobaba applied the EMSR to Western Airlines reservation data for 210 high-demand flights in 1987. When compared with the Western Airlines method of seat allocation, the EMSR increased revenue by 6.2 percent. The EMSR consistently allocated more seats to lower-fare classes than did the seat inventory analysts for the airlines. In some cases this proved to be highly advantageous, but in others it proved to be detrimental to overall revenue. Several problems were noticed, including that the fare differentials of Western were fairly low and that only the most basic formulation of the EMSR model was used. In addition, since only flights with high demand were used, a comparison of the methods for a variety of demand scenarios was not performed.

\section{Combining Mathematical Programming and Economics Approaches}

Curry (1988) developed equations which allow mathematical programming to handle nested problems. Since EMSR is good with nested problems, but can handle only legs, and mathematical programming can handle multiple origindestinations and side constraints, but cannot include nesting, a combination of the two approaches seems ideal. By proving that the expected revenue function for nested fare classes was convex, he was able to show that a piecewise linear approximation of the expected revenue function could be developed and that mathematical programming approaches can adequately handle nested problems.

The objective of his problem is to maximize revenue over the entire origin-destination network, subject to capacity constraints. The optimal solution gives booking limits for a given nest allocation which ensures maximum revenue whatever the allocation for the nest. Assumptions made by Curry do not vary much from those of Belobaba and include: 1) fare classes within a nest are ordered by value, 2) the lower value fares book first, 3) no cancellations occur in closed fare classes, 4) independent demand of fare classes, 5) a demand request denied represents lost revenue, and 6) no upgrades are allowed. 
Williamson (1988) tested six yield management methods: (1) leg-based EMSR, (2) prorated EMSR, (3) virtual nesting EMSR, (4) deterministic linear programming, (5) probabilistic linear programming, and (6) deterministic linear programming nested on shadow prices. The test problem, which consisted of flying from Atlanta to four cities, with the fare, and mean and standard deviation of three different levels of demand given, was evaluated for each of the methods.

The EMSR models were based on the work of Belobaba (1987). The leg-based EMSR was Belobaba's basic model, the prorated EMSR tries to allocate revenue over the appropriate flight leg, and the virtual nesting EMSR was an attempt by Belobaba to model the role of the network of flight legs. Deterministic linear programming was limited by the restriction of nonprobabilistic demand forecasts and that the use of distinct instead of nested inventories. The probabilistic linear programming was solved with a binary integer program in which the decision variables represented every possible seat. The objective was to maximize expected marginal revenue. Williamson then used the standard linear programming approach, but ordered the shadow prices in such as way as to give priority to those seats with the highest shadow price.

At low demand levels, deterministic linear programming gave the worst result, while probabilistic linear programming had the best performance. At medium and high levels of demand, the virtual nesting EMSR had the worst performance and probabilistic linear programming had the best performance. Unfortunately, the size of the probabilistic linear programming formulation was much too large, and would probably not be a practical approach for a firm which must dynamically allocate seats. The EMSR and prorated EMSR displayed similar results. Although they did not account for the network of flights, they proved easy to use and understand. The shadow price method worked well, but suffered from the limitation of deterministic, rather than probabilistic, demand.

\section{Threshold Curve Method}

Another method frequently used with yield management systems is the threshold curve (Cross (1986), Relihan (1989)). Much of the research on threshold curve methodology is proprietary, but it appears to be a popular yield management method used by many hotels and airlines. Essentially, data on past booking behavior over time (usually 60 to 90 days) are collected, curves based on historical aggregate demand patterns are constructed, and actual booking patterns are plotted against the forecast (Cross (1986)). Generally, different threshold curves are built for different days of the week and seasons of the year for particular blocks of inventory (individual hotels or flights). Given that some fluctuations in demand are likely to occur, an acceptable range of variation is calculated using standard deviations of demand (see Figure 2). If demand is higher than expected, one or more rate classes may be closed, while if demand is lower than expected, one or more rate classes may be opened. A simple threshold curve can be built using historical mean and standard deviations of demand, although many of the commercial applications of this methodology are fitted using cubic spline methodology. In

Figure 2, the heavy line represents the average demand, while the other lines represent between \pm .25 through \pm 2 standard deviations of demand. The function of the cubic spline methodology is to smooth out the threshold curves.

Belobaba (1986) views this approach as a statistical data management program which is not designed to find optimal booking limits. Despite this limitation, the threshold curve methodology is fairly simple to use and appears to give good 
FIGURE 2

THRESHOLD CURVE

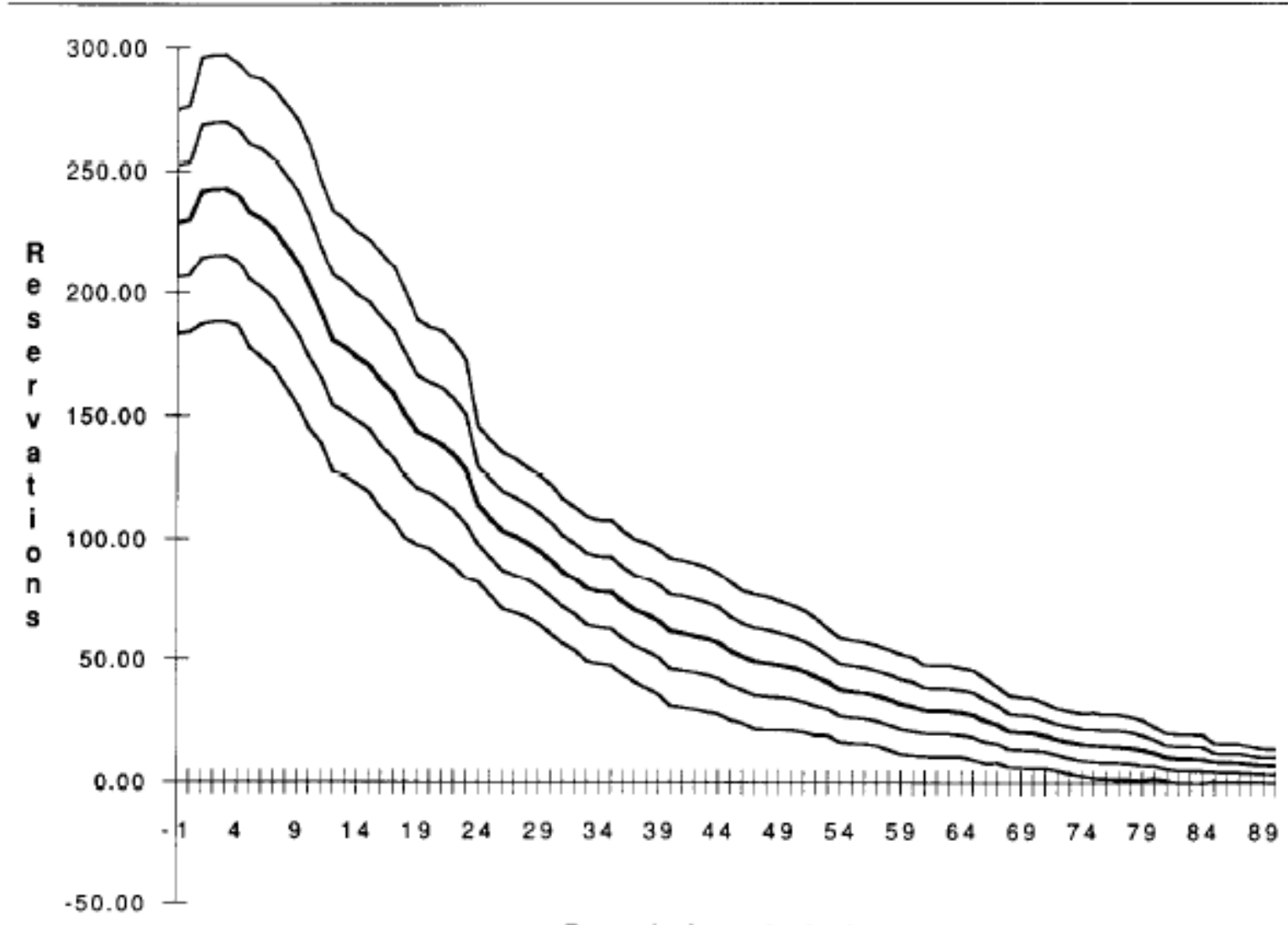

Days before Arrival

results. In addition, aggregate demand, rather than demand for different rate classes, is used to develop the threshold curve. As with other methods, the most critical problem is obtaining timely and accurate information.

\section{Expert Systems Approaches}

Several systems purporting to be expert system or neural network approaches have been developed, but too little information is available to assess their validity. Certainly, such an approach would be extremely useful to managers of capacity-constrained service organizations, but before adopting such a sophisticated method, managers must first be aware of the fundamentals of the problem with which they are faced.

\section{SPECIFIC PROBLEMS WITH YIELD MANAGEMENT TECHNIQUES}

Yield management techniques developed in one industry are not always immediately applicable to other industries. Yield management systems need to address the problems of multiple-phase services, such as legs of a flight, or multiplenight stays in a hotel. The multiplier effect of the inventory items (seats, rooms, cars) on other business functions must also be assessed.

Multi-phase services. Many services consist of more than one phase. For example, most airlines operate hub-and-spoke systems in which passengers purchase different flight legs, hotel guests may stay for more than one night, and car rental customers may rent the car for more than one day. Developing an optimal solution for the single phase of the service may 
not prove useful when considering the entire service network. Some commercial yield management systems have considered this problem on an ad hoc basis, but no published research systematically addresses this issue.

Multiplier effect. One of the underlying assumptions of yield management is that the inventory item being allocated is independent of other portions of the service business. For example, sales of airline seats does not affect other portions of the airline business. This assumption may be violated in some industries, such as the hotel industry, because customers purchase more than just rooms, and allocating reservations on only the basis of room rate may lead to less than optimal solutions when considering the overall revenue of the hotel.

\section{MANAGERIAL IMPLICATIONS OF YIELD MANAGEMENT SYSTEMS}

Very little has been written on the managerial implications associated with yield management. Yield management may give a firm a competitive edge, but it could also result in (1) a loss of competitive focus, (2) customer alienation, (3) severe employee morale problems, (4) a change in reward systems, and (5) a need for intensive employee training. As with any new approach to business, (6) proper organization and (7) a firm commitment from top management are essential.

(1) Loss of competitive focus. Since most yield management systems focus on maximizing revenue or yield, companies using such a system may develop an undue focus on short-term profits and ignore long-term profits which could result from managerial attention to producing and delivering good service. As Hayes and Abernathy (1980) point out, although financial success is imperative to any firm, an over-emphasis on short-term financial gains may lead to disastrous results. Many service organizations are successful because they offer very high quality services which are in high demand. The focus on efficient resource use that yield management implies may take managerial attention away from customer service, and fundamentally change the service concept. The net result may well be a loss of customers at considerable financial cost.

(2) Customer alienation. Consumers seem to be resigned to the fact that airlines charge different prices depending on how far ahead a ticket was bought, and on what restrictions were met, but will customers of other types of services do the same? In industries with only a few major competitors (such as the airline or rental car industries) this may work, but in industries with a large number of competitors (such as the hotel industry), a customer who does not like paying different prices for the same room may decide to patronize the competition. Likewise, customers may find it unfair to be paying a higher price for a service than someone who reserved it a few weeks earlier. Firms adopting yield management programs may face a consumer education problem.

(3) Employee morale problems. Yield management systems take much of the guess work out of how many items of inventory to sell at what price, but they also take some of the judgment out of the jobs of reservationists. Unless properly structured to allow for some judgment, yield management systems could be met with resentment from people having to use them.

(4) Incentive and reward systems. Yield management systems could also cause a problem for group sales departments. Typically, salespeople in such departments are rewarded by the amount of sales they make. With a yield management 
system, it might not be beneficial for the business to accept a group sale at a low rate when that block of inventory could be sold at a higher rate. Unless incentive systems are changed, group sales workers might find that yield management works against them.

In a similar vein, managers are often rewarded on the basis of capacity utilization or average rate. With a yield management system, the manager needs to be concerned with both of these factors. Unless the incentive system is changed to reflect this, managers may resent using yield management.

(5) Employee training. As with any new system, a yield management system will require extensive training of all employees. The employees must clearly understand the purpose of yield management, essentially how it works, and how it affects their jobs. Top management cannot assume that yield management will just happen: it requires careful planning and training.

(6) Organization of yield management function. One of the major problems confronting most firms adopting yield management systems is degree of centralization of reservations systems. Airlines have traditionally had highly centralized reservations systems, but other industries, such as the hotel, rental car, and freight shipment industries tend to have more decentralized reservations systems. This problem can be overcome by developing a strong information system which integrates both central and branch reservations systems.

In terms of what department within the business should be responsible for the yield management system, arguments for several departments (sales, operations, reservations, MIS) could be made. Ideally, all areas of the firm will be involved with the yield management program. Only when this occurs, will the program be truly successful.

(7) Top management commitment. Without a commitment from top management, yield management systems may be doomed to failure. Unless all employees know that the yield management system is considered essential to the success of the company, they may be inclined to treat it less seriously than top management may prefer.

\section{DIRECTIONS FOR FUTURE RESEARCH}

Research in yield management should address the following concerns.

(1) Integrate multiple-phase services into the solution technique. Solution methods which include provisions for multiple flight legs, multiple night stays, multiple services, and multiple rental days must be developed if yield management systems are to be truly useful.

(2) Develop a method for solving problems with nested rate structures. Nested rate structures seem to provide a more reasonable reservation model. Currently, only the EMSR (Belobaba (1987)) uses a nested rate structure. Mathematical programming methods which can use such a structure should be developed.

(3) Further develop solution techniques for quick and easy application. One of the major problems confronting firms considering yield management is the frequency with which the problem must be resolved. Optimal methods are of little value when they take a long time to solve. Solution techniques which lend themselves to quick and repetitive solution will prove invaluable to firms using yield management. 
(4) Analyze demand distributions and correlations. Demand distributions and correlations have been studied thoroughly in the airline industry, but no published research has addressed this issue in other capacity-constrained industries. Without knowing the probability distribution of demand, cancellations and overbooking, improper assumptions may be made, and the results from the yield management program may be highly inaccurate.

(5) Analyze model sensitivity to data. Models are often best designed for the data on which they were built (Mosteller and Tukey (1977)). Very little work on analyzing the performance of different methods on different types of data sets has been performed. This research would lend itself nicely to a simulation approach and would help determine which methods are better in which situations.

(6) Analyze booking rates over time. One of the most difficult factors that firms practicing yield management must face is collecting the information necessary for implementation. A thorough study of how reservations are made for various classes of service must be made and integrated into the yield management system.

(7) Incorporate pricing decisions into solution methods. Most current yield management approaches assume price is a given (Belobaba (1989)). Since yield management consists of both inventory management and pricing, techniques which can better integrate pricing into the yield management decisions would be extremely desirable.

(8) Develop centralized reservations and information systems. Since information availability is often a problem, developing a centralized information system is of utmost importance. If the firm cannot access its demand history easily, the yield management system will become unworkable.

\section{CONCLUSION}

Yield management presents a tremendous opportunity for profitably managing capacity in capacity-constrained service firms. Research on solution techniques is fairly advanced in the airline industry, but much is left to be done in other industries. Emphasis should be placed on developing quick and easy-to-use methods which can immediately begin producing results. Operations management researchers can provide an invaluable service to capacity-constrained firms by helping them manage their capacity more efficiently. 


\section{REFERENCE}

1. Alstrup, Jens, Soren Boas, Oli Madsen, and Rene Vidal. "Booking Policy for Flights with Two Types of Passengers." European Journal of Operations Research, vol. 27, 1986, 274-288.

2. Beckman, M.J. "Decision and Team Problems in Airline Reservations." Economelrica, vol. 26, 1958, 134-145.

3. Belobaba, Peter Paul. Air Travel Demand and Airline Seat Inventory Management. Unpublished doctoral dissertation, Massachusetts Institute of Technology, 1987.

4. Belobaba, Peter Paul. "Application of a Probabilistic Decision Model to Airline Seat Inventory Control." Operations Research, vol. 37, no. 2, 1989, 183-197.

5. Cross, Robert G. "Strategic Selling: Yield Management Techniques to Enhance Revenue." Presented to ShearsonLehman Brothers 1986 Airline Industry Seminar. Key Largo, Florida, February 1986.

6. Curry, Renwick E. "Optimum Airline Seat Allocation with Fare Classes Nested by Origins and Destinations." Unpublished paper, Aeronomics, Inc., 1988.

7. Deetman, C. "Booking Levels." AGIFORS Proceedings, vol. 4, 1964, 210-235.

8. Glover, Fred, Randy Glover, Joe Lorenzo, and Claude McMillan. "The Passenger-Mix Problem in the Scheduled Airlines." Interfaces, vol. 12, no. 3, 1982. 73-79.

9. Hayes, Robert H., and William J. Abernathy. (1980). "Managing Our Way to Economic Decline." Harvard Business Review, vol. 58, no. 4, 1980, 67-77.

10. Hersh, Marvin, and Shaul P. Ladany. "Optimal Seat Allocation for Flights with One Intermediate Stop." Computers and Operations Research, vol. 5, 1978, 31-37.

11. Ladany, Shaul R “Dynamic Operating Rules for Motel Reservations.” Decision Sciences, vol. 7, no. 4, 1976, 829-840.

12. Ladany, Shaul R “Bayesian Dynamic Operating Rules for Optimal Hotel Reservation." Z. Operations Research, vol. 21, 1977, B165-176.

13. Lieberman, V, and U. Yechialli. "On the Hotel Overbooking Problem: An Inventory Problem with Stochastic Cancellations." Management Science, vol. 24, 1978, 1117-1126.

14. Littlewood, Kenneth. "Forecasting and Control of Passenger Bookings." AGIFORS Proceedings, vol. 12, 1972, 95-117.

15. Lloyd's Aviation Economist. "Yield Managers Now Control Tactical Marketing." May 1985, 12-13.

16. Lovelock, Christopher. "Strategies for Managing Capacity-Constrained Service Organizations." Service Industries Journal, November 1984.

17. Martinez, R., and Sanchez, M. “Automated Booking Level Control." AGIFORS Proceedings, 1970.

18. Mosteller, Frederick, and John W. Tukey. Data Analysis and Regression. Reading, MA: Addison-Wesley, 1977.

19. Orkin, Eric B. "Boosting Your Bottom Line with Yield Management." Cornell Hotel and Restaurant Administration Quarterly, February 1988, 52-56.

20. Relihan, Walter J. "Yield Management Approach to Hotel-Room Pricing." Cornell Hotel and Restaurant Administration Quarterly, May 1989, 40-45.

21. Rothstein, Marvin. “An Airline Overbooking Model." Transportation Science, vol. 5, 1971, 180-192.

22. Rothstein, Marvin. "Hotel Overbooking as a Markovian Sequential Decision Process." Decision Sciences, vol. 5, 1974, 389-394.

23. Rothstein, Marvin. "Operations Research and the Airline Overbooking Problem." Operations Research, vol. 33, no. 2, $1985,237-248$.

24. Rothstein, Marvin, and A.W. Stone. "Passenger Booking Levels." AGIFORS Proceedings, vol. 7, 1967.

25. Schlifer, E., and Y. Vardi. "An Airline Overbooking Policy." Transportation Sciences, vol. 9, 1975, 101-114.

26. Taylor, C.J. "The Determination of Passenger Booking Levels." AGIFORS Proceedings, vol. 2, 1962, 93-116. 
27. Thompson, H.R. "Statistical Problems in Airline Reservation Control." Operational Research Quarterly, 12, 1961, 167185.

28. Toh, Rex. "Airline Revenue Yield Protection: Joint Reservation Control Over Full and Discount Fare Sales." Transportation Journal, Winter 1979, 74-80.

29. Toh, Rex. 'An Inventory Depletion Overbooking Model for the Hotel Industry. ' Journal of Travel Research, Spring 1985, 24-30.

30. Williams, Fred E. "Decision Theory and the Innkeeper: An Approach for Setting Hotel Reservation Policy." Interfaces, vol. 7 , no. 4, 1977, 18-30.

31. Williamson, Elizabeth L. Comparison of Optimization Techniques for Origin-Destination Seat Inventory Control. Unpublished MS thesis, Massachusetts Institute of Technology, 1988.

32. Wollmer, Richard D. "An Airline Reservation Model for Opening and Closing Fare Classes." Unpublished Douglas Aircraft report, 1989. 